\title{
The influence of Work Environment, Job Satisfaction, and Organizational Commitment on Employee Performance at PT Sun Star Motor Branch MT Haryono Semarang
}

\author{
Nanda Dania Ariani Widyastuti, Fatchun Hasyim*, Suharmanto \\ Applied Business Administration, State Politechnic of Semarang,Indonesia
}

\begin{abstract}
Employee performance of PT Sun Star Motor is affected by many factors. This research aims to analiyze the influence of work environment, job satisfaction, and organizational commitment on employee performance at PT Sun Star Motor Branch MT Haryono Semarang. The technique of analysis used is multiple linear regression. The population and sample are the entire of employees of PT Sun Star Motor Branch MT Haryono is 40 people. Data collection method used are questionnaire, participant observation and literature review. The results of $F$ test, shows that work environment, job satisfaction, and organizational commitment has significant affect on employee performance at PT Sun Star Motor Branch MT Haryono Semarang. Based on the results of the $t$ test, the work environment has a significant positive effect on the employee performance of PT Sun Star Motor Branch MT Haryono Semarang. Job satisfaction has no significant effect on employee performance at PT Sun Star Motor Branch MT Haryono Semarang. And organizational commitment has significant positive effect on employee performance at PT Sun Star Motor Branch MT Haryono Semarang. While the coefficient of determination (adjusted $R^{2}$ ) of employee performance is $61.8 \%$ which is explained by work environment, job satisfaction, and organizational commitment. The remaining $38.2 \%$ is influenced by other factors outside the model.
\end{abstract}

Keywords: work environment, job satisfaction, organizational commitment, employee performance 


\title{
Pengaruh Lingkungan Kerja, Kepuasan Kerja, dan Komitmen Organisasi terhadap Kinerja Karyawan pada PT Sun Star Motor Cabang MT Haryono Semarang
}

\begin{abstract}
Abstrak
Kinerja karyawan PT Sun Star Motor dipengaruhi oleh banyak faktor. Penelitian ini bertujuan untuk menganalisis pengaruh lingkungan kerja, kepuasan kerja, dan komitmen organisasi terhadap kinerja karyawan pada PT Sun Star Motor Cabang MT Haryono Semarang. Teknik analisis yang digunakan adalah regresi linier berganda. Populasi dan sampel adalah seluruh karyawan PT Sun Star Motor Cabang MT Haryono yang berjumlah 40 orang. Metode pengumpulan data yang digunakan adalah angket, observasi partisipan dan studi pustaka. Hasil uji F menunjukkan bahwa lingkungan kerja, kepuasan kerja, dan komitmen organisasi berpengaruh signifikan terhadap kinerja karyawan pada PT Sun Star Motor Cabang MT Haryono Semarang. Berdasarkan hasil uji t, lingkungan kerja berpengaruh positif signifikan terhadap kinerja karyawan PT Sun Star Motor Cabang MT Haryono Semarang. Kepuasan kerja berpengaruh tetapi tidak signifikan terhadap kinerja karyawan pada PT Sun Star Motor Cabang MT Haryono Semarang. Dan komitmen organisasi berpengaruh positif signifikan terhadap kinerja karyawan pada PT Sun Star Motor Cabang MT Haryono Semarang. Sedangkan koefisien determinasi (adjusted $\mathrm{R}^{2}$ ) kinerja karyawan sebesar 61,8\% yang dijelaskan oleh lingkungan kerja, kepuasan kerja, dan komitmen organisasi. Sisanya sebesar 38,2\% dipengaruhi oleh faktor lain di luar model.
\end{abstract}

Kata Kunci: lingkungan kerja, kepuasan kerja, komitmen organisasi, kinerja karyawan 


\section{PENDAHULUAN}

Perkembangan bisnis di era globalisasi yang begitu pesat menuntut perusahaan untuk menunjukkan kinerja terbaik dengan seluruh sumber daya yang dimilikinya. Perusahaan sangat membutuhkan sumber daya manusia yang berkualitas untuk mencapai tujuan perusahaan yang telah ditentukan. Manajemen Sumber Daya Manusia (MSDM) merupakan potensi manusiawi yang berperan sebagai penggerak organisasi dalam mewujudkan eksistensinya.

Pengelolaan sumber daya manusia dalam perusahaan perlu dilakukan, salah satu caranya yaitu dengan meningkatkan kualitas dari kinerja MSDM (Manajemen Sumber Daya Manusia) yang dimilikinya. Setiap perusahaan selalu mengharapkan karyawannya mempunyai kinerja yang baik, karena dengan karyawan yang memiliki kinerja yang baik akan memberikan sumbangan yang optimal bagi perusahaan. Selain itu, dengan memiliki karyawan yang mempunyai kinerja baik perusahaan dapat meningkatkan kinerja perusahaannya. Sehingga kelangsungan suatu perusahaan sangat ditentukan oleh kinerja karyawannya (Chintia, 2016). Pengelolaan sumber daya manusia yang baik merupakan salah satu kunci keberhasilan perusahaan dalam mencapai tujuan tersebut.

PT Sun Star Motor Cabang MT Haryono Semarang merupakan perusahaan di bidang perdagangan otomotif khususnya mobil. Dan dalam bidang tersebut kinerja karyawannya sangat berperan penting dalam perdagangan otomotif. Kinerja karyawan ditunjukkan dari tingkat ketepatan waktu dan kehadiran karyawan dalam bekerja. Karyawan bekerja selama 8 jam per hari dimana setiap karyawan wajib melakukan absensi saat datang dan pulang. Ketidakhadiran karyawan juga cenderung mengalami kenaikan perbulannya pada PT Sun Star Motor Cabang MT Haryono Semarang. Tingkat keterlambatan dan ketidakhadiran karyawan akan berpengaruh pada berkurangnya jumlah jam kerja yang dapat digunakan untuk menyelesaikan program kerja atau kegiatan perusahaan. Menurut Shanty (2019:108), menurunnya kinerja karyawan dapat disebabkan oleh lingkungan kerja yang tidak memuaskan sehingga dapat menurunkan semangat kerja dan juga menurunkan kinerja karyawan. Lingkungan kerja merupakan segala sesuatu yang ada di sekitar tempat kerja baik secara fisik maupun non fisik. Kepuasan kerja karyawan yang tidak tercapai karena tekanan pekerjaan yang tinggi dapat mempengaruhi pekerjaan mereka. Selain itu, dapat disebabkan karena kurangnya komitmen organisasi dari karyawan yang dapat dilihat dari karyawan yang datang tidak tepat waktu dan sikap santai dan mengobrol saat bekerja.

Dari uraian diatas penulis berpendapat bahwa perlu penelitian mengenai "Pengaruh Lingkungan Kerja, Kepuasan Kerja, dan Komitmen Organisasi terhadap Kinerja Karyawan pada PT Sun Star Motor Cabang MT Haryono Semarang".

\section{Perumusan Masalah}

Berdasarkan uraian diatas, perumusan masalah dalam penelitian ini adalah sebagai berikut:

a. Bagaimana pengaruh lingkungan kerja terhadap kinerja karyawan pada PT Sun Star Motor Cabang MT Haryono Semarang?

b. Bagaimana pengaruh kepuasan kerja terhadap kinerja karyawan pada PT Sun Star Motor Cabang MT Haryono Semarang?

c. Bagaimana pengaruh komitmen organisasi terhadap kinerja karyawan pada PT Sun Star Motor Cabang MT Haryono Semarang?

d. Bagaimana pengraruh lingkungan kerja, kepuasan kerja dan komitmen organisasi terhadap kinerja karyawan PT Sun Star Motor Cabang MT Haryono Semarang?

\section{Tujuan Penelitian}

Adapun tujuan yang ingin dicapai dalam penulisan ini adalah sebagai berikut: 
a. Menganalisis pengaruh lingkungan kerja terhadap kinerja karyawan pada PT Sun Star Motor Cabang MT Haryono Semarang.

b. Menganalisis pengaruh kepuasan kerja terhadap kinerja karyawan pada PT Sun Star Motor Cabang MT Haryono Semarang.

c. Menganalisis pengaruh komitmen organisasi terhadap kinerja karyawan pada PT Sun Star Motor Cabang MT Haryono Semarang.

d. Menganalisis pengaruh lingkungan kerja, kepuasan kerja dan komitmen organisasi terhadap kinerja karyawan PT Sun Star Cabang Motor MT Haryono Semarang.

\section{Tinjauan Pustaka}

\section{Kinerja Karyawan}

Menurut Cokroaminoto dalam Fauzi (2016) kinerja karyawan yaitu menunjuk pada kemampuan karyawan dalam melaksanakan keseluruhan tugas-tugas yang menjadi tanggungjawabnya.

\section{Indikator Kinerja Karyawan}

Menurut Bernardin dan Russel dalam Nasution (2019:10) yang digunakan untuk mengukur kinerja karyawan dalam penelitian ini adalah sebagai berikut :
a. Kualitas kerja
b. Kuantitas kerja
c. Kerjasama

\section{Lingkungan Kerja}

Menurut Sedarmayanti dalam Shanty (2019:105), lingkungan kerja adalah keseluruhan alat perkakas, bahan yang dihadapi, dan lingkungan sekitarnya dimana seorang bekerja, metode kerjanya serta pengaturan kerjanya baik sebagai perseorangan maupun sebagai kelompok.

\section{Indikator Lingkunga Kerja}

Menurut Sedarmayanti dalam Intan (2017:47) yang digunakan dalam penelitian ini untuk mengukur lingkungan kerja yaitu:

a. Tempatur udara
b. Hubungan karyawan
c. Kebisingan

\section{Kepuasan Kerja}

Menurut Luthans dalam Changgriawan (2017), kepuasan kerja karyawan adalah perasaan positif yang terbentuk dari penilaian karyawan terhadap pekerjaannya berdasarkan persepsi karyawan mengenai seberapa baik pekerjaannya, yang berarti bahwa apa yang diperoleh dalam bekerja sudah memenuhi apa yang dianggap penting.

\section{Indikator Kepuasan Kerja}

Menurut Alshitri dalam Wateknya (2016:473), yang digunakan untuk mengukur kepuasan kerja yaitu:

a. Coworkers (kepuasan terhadap rekan kerja)

b. Nature of work (kepuasan terhadap pekerjaan itu sendiri)

c. Supervision (kepuasan terhadap atasan)

\section{Komitmen Organisasi}

Menurut Zurnali dalam Sari (2019:2) bahwa komitmen organisasi merupakan perasaan yang kuat dan erat dari seseorang terhadap tujuan dan nilai suatu organisasi dalam hubungannya dengan peran mereka terhadap upaya pencapaian tujuan dan nilainilai tersebut.

\section{Indikator Komitmen Organisasi}

Menurut Meyer dan Allen dalam Widiastuti (2017:87) menyebutkan terdapat tiga indikator dalam komitmen organisasi, yaitu:
a. Komitmen
Afektif
(Affective commitment)
b. Komitmen Kontinyu (continuance commitment)
c. Komitmen normatif (normative commitment) 


\section{METODE PENELITIAN}

\section{Populasi dan Sampel}

Di dalam penelitian ini, yang menjadi populasi yaitu seluruh karyawan PT Sun Star Motor MT Haryono Cabang Semarang, Teknik sampel yang digunakan yaitu sampling jenuh, dan jumlah sampel yang digunakan berjumlah 40 responden.

\section{Teknik Pengumpulan Data}

Teknik pengumpulan data yang digunakan dalam penelitian ini yaitu observasi, kuesioner dan studi pustaka. Kuesioner yang digunakan dalam penelitian ini adalah skala pengukuran likert dengan rentang 1-5.

\section{Teknik Pengumpulan Data}

Teknik analisis yang digunakan dalam penelitian ini yaitu analisis regresi linear berganda dengan menggunakan SPSS 24. Hasil analisis data terdiri dari uji validitas dan uji reliabilitas, uji asumsi klasik, dan uji signifikansi.

\section{HASIL DAN PEMBAHASAN Uji Validitas}

Uji validitas menurut Ghozali (2018:89) digunakan untuk mengetahui kelayakan butir-butir dalam suatu daftar pertanyaan dalam mendefinisikan suatu variabel. Berdasarkan Tabel 1 dapat disimpulkan bahwa semua indikator variabel Lingkungan Kerja, Kepuasan Kerja, Komitmen Organisasi dan Kinerja Karyawan adalah valid. 
Tabel 1 Hasil Uji Validitas

\begin{tabular}{|c|c|c|c|c|}
\hline Variabel & $\begin{array}{c}\text { Item } \\
\text { Pertanyaan }\end{array}$ & $\mathbf{r}_{\text {hitung }}$ & $\mathrm{r}_{\text {tabel }}$ & Keterangan \\
\hline \multirow{9}{*}{$\begin{array}{c}\text { Lingkungan } \\
\text { Kerja (X1) }\end{array}$} & $\mathrm{X} 1.1$ & 0,453 & 0,312 & Valid \\
\hline & $\mathrm{X} 1.2$ & 0,488 & 0,312 & Valid \\
\hline & $\mathrm{X} 1.3$ & 0,507 & 0,312 & Valid \\
\hline & $\mathrm{X} 1.4$ & 0,432 & 0,312 & Valid \\
\hline & $\mathrm{X} 1.5$ & 0,438 & 0,312 & Valid \\
\hline & X1.6 & 0,478 & 0,312 & Valid \\
\hline & $\mathrm{X} 1.7$ & 0,677 & 0,312 & Valid \\
\hline & $\mathrm{X} 1.8$ & 0,683 & 0,312 & Valid \\
\hline & X1.9 & 0,706 & 0,312 & Valid \\
\hline \multirow{9}{*}{$\begin{array}{l}\text { Kepuasan } \\
\text { Kerja (X2) }\end{array}$} & $\mathrm{X} 2.1$ & 0,532 & 0,312 & Valid \\
\hline & $\mathrm{X} 2.2$ & 0,586 & 0,312 & Valid \\
\hline & $\mathrm{X} 2.3$ & 0,47 & 0,312 & Valid \\
\hline & $\mathrm{X} 2.4$ & 0,495 & 0,312 & Valid \\
\hline & $\mathrm{X} 2.5$ & 0,549 & 0,312 & Valid \\
\hline & $\mathrm{X} 2.6$ & 0,428 & 0,312 & Valid \\
\hline & $\mathrm{X} 2.7$ & 0,84 & 0,312 & Valid \\
\hline & $\mathrm{X} 2.8$ & 0,517 & 0,312 & Valid \\
\hline & X2.9 & 0,560 & 0,312 & Valid \\
\hline \multirow{9}{*}{$\begin{array}{l}\text { Komitmen } \\
\text { Organisasi } \\
\quad \text { (X3) }\end{array}$} & X3.1 & 0,426 & 0,312 & Valid \\
\hline & X3.2 & 0,657 & 0,312 & Valid \\
\hline & X3.3 & 0,653 & 0,312 & Valid \\
\hline & X3.4 & 0,865 & 0,312 & Valid \\
\hline & $\mathrm{X} 3.5$ & 0,717 & 0,312 & Valid \\
\hline & X3.6 & 0,831 & 0,312 & Valid \\
\hline & X3.7 & 0,677 & 0,312 & Valid \\
\hline & X3.8 & 0,858 & 0,312 & Valid \\
\hline & X3.9 & 0,798 & 0,312 & Valid \\
\hline \multirow{9}{*}{$\begin{array}{c}\text { Kinerja } \\
\text { Karyawan } \\
(\mathrm{Y})\end{array}$} & Y1.1 & 0,717 & 0,312 & Valid \\
\hline & Y1.2 & 0,881 & 0,312 & Valid \\
\hline & Y1.3 & 0,708 & 0,312 & Valid \\
\hline & Y1.4 & 0,763 & 0,312 & Valid \\
\hline & Y1.5 & 0,706 & 0,312 & Valid \\
\hline & Y1.6 & 0,728 & 0,312 & Valid \\
\hline & Y1.7 & 0,660 & 0,312 & Valid \\
\hline & Y1.8 & 0,673 & 0,312 & Valid \\
\hline & Y1.9 & 0,800 & 0,312 & Valid \\
\hline
\end{tabular}

Sumber: Data primer yang diolah, 2020

\section{Uji Reliabilitas}

Uji reliabilitas menurut Ghozali (2018:45) bertujuan untuk mengetahui sejauh mana suatu hasil pengukuran relative konsisten bila pengukuran diulang dua kali atau lebih. 
Tabel 2. Hasil Uji Reliabilitas

\begin{tabular}{|l|c|c|c|}
\hline \multicolumn{1}{|c|}{ Variabel } & $\begin{array}{c}\text { Cronbach's } \\
\text { Alpha }\end{array}$ & $\begin{array}{c}\text { Standart } \\
\text { Alpha }\end{array}$ & Keterangan \\
\hline Lingkungan Kerja (X1) & 0,701 & 0,6 & Reliabel \\
\hline Kepuasan Kerja (X2) & 0,682 & 0,6 & Reliabel \\
\hline Komitmen Organisasi (X3) & 0,891 & 0,6 & Reliabel \\
\hline Kinerja Karyawan (Y) & 0,896 & 0,6 & Reliabel \\
\hline
\end{tabular}

Sumber: Data primer yang diolah, 2020

Dari Tabel 2 dapat dilihat bahwa keempat variabel yang digunakan dalam penelitian ini dinyatakan reliabel karena nilai Cronbach Alpha masing-masing variabel tersebut lebih dari 0.6.

\section{Uji Asumsi Klasik}

\section{Uji Normalitas}

Uji normalitas menurut Ghozali (2018:161) berguna untuk mengetahui apakah populasi data berdistribusi normal atau tidak. Berdasarkan hasil uji normalitas menggunakan Shapiro Wilk, didapatkan nilai signifikan sebesar 0.117 lebih besar dari 0.05, maka data dinyatakan berdistribusi normal.

\section{Uji Multikolonieritas}

Berdasarkan dari hasil uji Multikolonieritas menunjukkan bahwa variabel Lingkungan Kerja nilai tolerance sebesar 0.754 dan nilai VIF sebesar 1.325, variabel Kepuasan Kerja nilai tolerance sebesar 0.773 nilai VIF sebesar 1.294, serta variabel Komitmen Organisasi nilai tolerance sebesar 0.605 dan nilai VIF sebesar 1.652, sehingga dapat disimpulkan bahwa tidak terdapat masalah multikolinearitas.

\section{Uji Heteroskedastisitas}

Uji Heteroskedastisitas menurut Ghozali (2018:137) bertujuan untuk menguji apakah dalam model regresi terjadi ketidaksamaan varian dari residual satu pengamatan ke pengamatan lain.

Berdasarkan hasil uji heteroskedastisitas menujukkan bahwa apabila titik-titiknya membentuk pola yang tidak teratur dan menyebar di atas dan di bawah angka 0 (nol) pada sumbu Y, maka penelitian ini lolos uji heteroskedastisitas

\section{Analisis Regresi Linear Berganda}

Analisis regresi linear berganda digunakan untuk mengetahui seberapa besar pengaruh variabel bebas (variabel independen) terhadap variabel terikat (variabel dependen).

Tabel 3. Hasil Analisis Regresi

\begin{tabular}{|c|c|c|c|c|c|c|}
\hline \multicolumn{7}{|c|}{ Coefficients $^{\mathrm{a}}$} \\
\hline \multirow{2}{*}{\multicolumn{2}{|c|}{ Model }} & \multicolumn{2}{|c|}{$\begin{array}{l}\text { Unstandardized } \\
\text { Coefficients }\end{array}$} & \multirow{2}{*}{$\begin{array}{c}\text { Standardized } \\
\text { Coefficients } \\
\text { Beta } \\
\end{array}$} & \multirow[b]{2}{*}{$\mathrm{t}$} & \multirow[b]{2}{*}{ Sig. } \\
\hline & & B & Std. Error & & & \\
\hline 1 & (Constant) & 1.727 & 6.853 & & .252 & .802 \\
\hline & $\mathrm{X} 1$ & .427 & .195 & .250 & 2.194 & .035 \\
\hline & $\mathrm{X} 2$ & .033 & .139 & .026 & .234 & .816 \\
\hline & X3 & .499 & .099 & .639 & 5.026 & .000 \\
\hline
\end{tabular}

Sumber: Data primer yang diolah, 2020 
Berdasarkan Tabel 3 dapat dibuat persamaan regresi sebagai berikut:

$$
\begin{array}{cccc}
Y=1,7 & +0,4 & X_{1}+0,0 & X_{2} \\
& +0,4 & X_{3} &
\end{array}
$$

Hasil persamaan regresi linear berganda tersebut memberikan pengertian bahwa:

a. Konstanta $(\alpha=1,727)$

Konstanta sebesar 1,727 berarti apabila variabel keteladanan pemimpin (X1), lingkungan kerja non fisik (X2) dan balas jasa (X3) sama dengan nol, maka variabel disiplin kerja (Y) sebesar 1,727 .

b. Koefisien $\mathrm{X}_{1}=0,427$

Koefisien regresi variabel lingkungan kerja (X1) bernilai positif yang berarti bahwa setiap kenaikan variabel lingkungan kerja maka kinerja karyawan (Y) akan meningkat.

c. Koefisien $\mathrm{X}_{2}=0,033$

Koefisien regresi variabel kepuasan kerja (X2) bernilai positif yang berarti bahwa setiap kenaikan variabel kepuasan kerja kerja maka kinerja karyawan (Y) akan meningkat.

d. Koefisien $\mathrm{X}_{3}=0,499$

Koefisien regresi variabel komitmen organisasi (X3) bernilai positif yang berarti bahwa setiap kenaikan variabel komitmen organisasi kerja maka kinerja karyawan (Y) akan meningkat.

\section{Uji Signifikan}

\section{Uji t (Uji Parsial)}

Uji $t$ menurut Ghozali (2018:86) digunakan untuk mengetahui pengaruh masing-masing variabel independen terhadap variabel dependen.

a. Pengujian Hipotesis Lingkungan Kerja (X1) terhadap Kinerja Karyawan (Y)

$\mathrm{H}_{\mathrm{o} 1}=$ Lingkungan Kerja tidak berpengaruh signifikan terhadap Kinerja

Karyawan pada PT Sun Star Motor Cabang MT Haryono Semarang.

$$
\begin{aligned}
& \mathrm{H}_{\mathrm{a} 1} \quad=\text { Lingkungan Kerja } \\
& \text { berpengaruh signifikan terhadap } \\
& \text { Kinerja } \\
& \text { Karyawan pada PT Sun } \\
& \text { Star Motor Cabang MT Haryono } \\
& \text { Semarang. }
\end{aligned}
$$

Pada hasil pengujian yang dilakukan $\mathrm{t}$ hitung Lingkungan Kerja sebesar 2,194 lebih besar dari t tabel sebesar 2,02619 dan nilai sig. 0,035. Karena nilai $t_{\text {hitung }}>t_{\text {tabel }}(2,194>$ 2,02619) dan nilai signifikansi $<0,05$ maka $\mathrm{H}_{01}$ ditolak dan $\mathrm{H}_{\mathrm{a} 1}$ diterima, maka dapat dinyatakan bahwa terdapat pengaruh signifikan antara lingkungan kerja terhadap kinerja karyawan.

b. Pengujian Hipotesis Kepuasan Kerja (X2) terhadap Kinerja Karyawan (Y)

$$
\begin{array}{rlr}
\text { Ho2 } & =\text { Kepuasan Kerja tidak } \\
& \text { berpengaruh signifikan terhadap } \\
& \text { Kinerja } \\
& \text { Karyawan pada PT Sun } \\
& \text { Star Motor Cabang MT Haryono } \\
& \text { Semarang. } \\
\text { Ha2 } & \text { Kepuasan } \\
& \text { berpengaruh signifikan terhadap } \\
& \text { Kinerja Karyawan } \\
& \text { pada PT Sun Star Motor } \\
& \text { Cabang MT Haryono Semarang. }
\end{array}
$$

Pada hasil pengujian yang dilakukan $\mathrm{t}$ hitung kepuasan kerja adalah 0,234 dan $t_{\text {tabel }}$ 2,02619 dan nilai sig. 0,816. Karena nilai $t_{\text {hitung }}<t_{\text {tabel }}(0,234<2,02619)$ dan nilai signifikansi $<0,05$ maka $\mathrm{H}_{02}$ diterima dan $\mathrm{H}_{\mathrm{a} 2}$ ditolak, maka dapat dinyatakan bahwa kepuasan kerja tidak berpengaruh signifikan terhadap kinerja karyawan pada PT Sun Star Motor Cabang MT Haryono Semarang.

c. Pengujian Hipotesis Komitmen Organisasi (X3) terhadap Kinerja Karyawan (Y)

$$
\begin{array}{lll}
\text { Ho3 } & =\text { Komitmen } & \text { Organisasi } \\
& \text { tidak berpengaruh } & \text { signifikan } \\
\text { terhadap Kinerja } &
\end{array}
$$


Karyawan pada PT Sun Star Motor Cabang MT Haryono Semarang.

Ha3 = Komitmen Organisasi berpengaruh signifikan terhadap Kinerja

Karyawan pada PT Sun Star Motor Cabang MT Haryono Semarang.

Pada hasil pengujian yang dilakukan $t$ hitung komitmen organisasi adalah 5,026 dan $\mathrm{t}_{\text {tabel }} 2,02619$ dan nilai sig. 0,000 . Karena nilai $t_{\text {hitung }}>t_{\text {tabel }}(5,026>2,02619)$ dan nilai signifikansi $<0,05$ maka $\mathrm{H}_{03}$ ditolak dan $\mathrm{H}_{\mathrm{a} 3}$ diterima, maka dapat dinyatakan bahwa terdapat pengaruh signifikan antara komitmen organisasi terhadap kinerja karyawan

\section{Uji F (Uji Simultan)}

Uji F menurut Ghozali (2018) semua variabel independen yang dimasukan dalam model mempunyai pengaruh secara bersamasama terhadap variabel dependen.

$\begin{aligned} & \text { Ho4 } \text { Secara bersama-sama } \\ & \text { lingkungan kerja, kepuasan kerja } \\ & \text { dan } \\ & \text { komitmen organisasi tidak } \\ & \text { berpengaruh secara signifikan } \\ & \text { terhadap }\end{aligned}$

kinerja karyawan PT Sun Star Motor Cabang MT Haryono Semarang.

Ha4 = Secara bersama-sama lingkungan kerja, kepuasan kerja dan

komitmen organisasi berpengaruh secara signifikan terhadap kinerja

karyawan PT Sun Star Motor Cabang MT Haryono Semarang.

Pada hasil pengujian yang dilakukan $\mathrm{F}$ hitung sebesar 22.030 sedangkan $\mathrm{F}$ tabel sebesar 2.87. $F_{\text {hitung }}>F_{\text {tabel }}(22,030>2,87)$ dan nilai signifikansi $0,000<0,05$, maka $\mathrm{H}_{04}$ ditolak dan $\mathrm{H}_{\mathrm{a} 4}$ diterima, artinya bahwa variabel independen (lingkungan kerja, kepuasan kerja, dan komitmen organisasi) secara simultan berpengaruh signifikan terhadap variabel dependen (kinerja karyawan).

\section{Koesfisien Determinasi}

Menurut Ghozali (2018) koefisien determinasi $\left(\mathrm{R}^{2}\right)$ pada dasarnya mengukut seberapa jauh kemampuan model dalam menerangkan variabel dependen.

Tabel 4 Koefisien Determinasi Model Summary ${ }^{b}$

\begin{tabular}{|l|r|r|r|r|}
\hline Model & R & R Square & $\begin{array}{c}\text { Adjusted R } \\
\text { Square }\end{array}$ & $\begin{array}{c}\text { Std. Error of } \\
\text { the Estimate }\end{array}$ \\
\hline 1 & $.805^{\mathrm{a}}$ & .647 & .618 & 2.313925 \\
\hline
\end{tabular}

a. Predictors: (Constant), X3,X2,X1

b. Dependent Variable: Y

Sumber: Data primer yang diolah, 2020

Pada Tabel 4 diketahui bahwa nilai adjusted $R$ square sebesar 0,618, yang berarti $61,8 \%$ variabel tetap kinerja karyawan dapat dijelaskan oleh ketiga variabel bebas yaitu lingkungan kerja, kepuasan kerja, dan komitmen organisasi. Sedangkan sebesar
$38,2 \%$ lainnya dijelaskan oleh variabel lainnya diluar penelitian ini.

\section{KESIMPULAN}

Kesimpulan dari penelitian mengenai pengaruh lingkungan kerja, kepuasan kerja, 
dan komitmen organisasi terhadap kinerja karyawan pad PT Sun Star Motor Cabang MT Haryono Semarang.

a. Berdasarkan hasil uji $t$ variabel Lingkungan Kerja dan Komitmen Organisasi secara parsial berpengaruh positif terhadap Kinerja Karyawan PT Sun Star Motor Cabang MT Haryono Semarang. Sedangkan hasil uji t variabel Kepuasan Kerja tidak berpengaruh signifikan terhadap kinerja karyawan PT Sun Star Motor Cabang MT Haryono Semarang.

b. Berdasarkan hasil uji F variabel lingkungan kerja, kepuasan kerja, dan komitmen organisasi secara simultan berpengaruh signifikan terhadap kinerja karyawan PT Sun Star Motor Cabang MT Haryono Semarang.

c. Berdasarkan nilai koefisien determinasi (adjusted R square) diperoleh hasil 0,618 $=61,8 \%$. Hal ini menunjukkan bahwa variabel lingkungan kerja, kepuasan kerja, dan komitmen organisasi mempengaruhi kinerja karyawan sebesar $61,8 \%$, dan selebihnya 38,2\% dipengaruhi oleh faktor lain di luar penelitian ini.

\section{Saran}

Berdasarkan hasil penelitian pada PT Sun Star Motor Cabang MT Haryono Semarang terdapat beberapa saran yang diajukan adalah sebagai berikut:

a. Lingkungan kerja $\left(\mathrm{X}_{1}\right)$, merupakan variabel yang mempunyai pengaruh terhadap kinerja karyawan pada PT Sun Star Motor Cabang MT Haryono Semarang. Adapun saran yang dapat diberikan terkait lingkungan kerja adalah perusahaan dapat melengkapi atau memperbaiki fasilitas-fasilitas perusahaan yang ada agar karyawan merasa nyaman dan aman.

b. Komitmen organisasi $\left(\mathrm{X}_{3}\right)$, merupakan variabel yang mempunyai pengaruh terhadap kinerja karyawan pada PT Sun Star Motor Cabang MT Haryono
Semarang. Adapun saran yang dapat diberikan terkait komitmen organisasi adalah dengan melakukan sosialisasi atas kebijakan-kebijakan di dalam organisasi yang merata kepada seluruh jajaran karyawan. Agar karyawan lebih paham terhadap kondisi perusahaan. Dukungan terhadap karyawan harus diperkuat dan harus secara rutin diadakan pertemuan, baik yang sifatnya formal maupun non formal. Agar timbul kemauan untuk bekerja demi organisasi dan keinginan yang kuat untuk tetap menjadi anggota organisasi.

\section{DAFTAR PUSTAKA}

Can, A., \& Yasri, Y. (2016). Pengaruh Motivasi Kerja, Kepuasan Kerja Dan Komitmen Organisasi Terhadap Kinerja Karyawan Pada Bank Nagari. Jurnal Riset Manajemen Bisnis dan Publik, 4(1).

Changgriawan, G. S. (2017). Pengaruh kepuasan kerja dan motivasi kerja terhadap kinerja karyawan di One Way Production. Agora, 5(2).

http://publication.petra.ac.id/index.php/manaj emenbisnis/article/view/6095/5593

Chintia Pristiyanti, D. I. T. A. (2016). Pengaruh Motivasi Kerja Dan Kepuasan Kerja Terhadap Kinerja Karyawan Pt. Mayer Sukses Jaya. Jurnal Ilmu Manajemen (JIM), 4(1).

Fadhil, A., \& Mayowan, Y. (2018). Pengaruh Motivasi Kerja Dan Kepuasan Kerja Terhadap Kinerja Karyawan AJB Bumiputera. Jurnal Administrasi Bisnis, 54(1), 40-47.

Fauzi, M., Warso, M. M., \& Haryono, A. T. (2016). Pengaruh Budaya Organisasi Dan Kepuasan Kerja Terhadap Kinerja Karyawan Dengan Komitmen Organisasi Sebagai Variabel Intervening (Studi Pada Karyawan PT. Toys Games Indonesia Semarang). Journal of Management, 2(2).

Ghozali, Imam. 2018. Aplikasi Analisis Multivariete Dengan Program IBM SPSS 
19.Edisi 9. Universitas Dipenoero: Semarang

Ginting, I. P. B. (2019). Pengaruh Gaya Kepemimpinan, Motivasi dan Lingkungan Kerja Terhadap Kinerja Pegawai Puskesmas Stabat Lama Kecamatan Wampu.

Intan, Tiya P.S. 2018. Pengaruh Lingkungan Kerja Dan Disiplin Kerja Terhadap Kinerja Pegawai. Jurnal Repository UIN Jakarta. 22 Februari 2018.

Iswandi, T., Djaelani, A. K., \& Priyono, A. A. (2018). Pengaruh Kepercayaan Pada Atasan, Komitmen Organisasi Dan Kepuasan kerja Terhadap Produktivitas Karyawan (Studi Empiris pada Bagian Umum Di Balai Kota Malang Periode 2018). Jurnal Ilmiah Riset Manajemen, 7(4).

Mustapa, A., Paramita, P. D., \& Hasiholan, L. B. (2018). Pengaruh Kualitas Produk, Harga Produk, Dan Keragamaan Produk Sparepart Toyota Terhadap Minat Beli Ulang Konsumen Dengan Kepuasaan Pelanggan Sebagai Variabel Intervening (Studi Pelanggan PT. New Ratna Motor Semarang). Journal

Management, 4(4).

Nasution, H. (2019). Pengaruh Lingkungan Kerja dan Disiplin Kerja Terhadap Kinerja Karyawan (Studi Kasus Pada UD. Artomoro Farm) (Doctoral dissertation, University of Muhammadiyah Malang).

Nurhidayah, S., \& Umam, M. O. H. (2018). Pengaruh Lingkungan Kerja Terhadap Kinerja Karyawan Dengan Motivasi Kerja Sebagai Variabel Mediasi (Doctoral dissertation, Institut Agama Islam Negeri Surakarta).

Saleh, F., Mashita, J., \& Anggresta, V. (2019). Pengaruh Lingkungan Kerja dan Komitmen Organisasi terhadap Kinerja Karyawan PT. Andalan Finance Depok. JABE (Journal of Applied Business and Economic), 6(1), 32-44.

Sapitri, R., \& Suryalena, S. (2016). Pengaruh komitmen organisasi terhadap kinerja karyawan Perusahaan Listrik Negara area Pekanbaru (Doctoral dissertation, Riau University).

Saputra, A. T., Bagia, I. W., Si, M., Yulianthini, N. N., \& SE, M. (2016). Pengaruh kepuasan kerja dan loyalitas karyawan terhadap kinerja karyawan. Jurnal Manajemen Indonesia, 4(1). https://ejournal.undiksha.ac.id/index.php/ JMI/article/view/6730/4591

Sari, P. A. P. (2019). Pengaruh Komitmen Organisasi Terhadap Kinerja Karyawan Pt Masa Kini Mandiri (Surat Kabar Harian Umum Lampung Post).

Setiawan, N. T. (2016). Hubungan Komitmen Organisasi Dengan Produktivitas Kerja Sales Pt. Ijmg Suzuki Surabaya (Doctoral dissertation, UIN Sunan Ampel Surabaya).

Shanty, D., \& Mayangsari, S. (2019). Analisis Pengaruh Kompensasi, Motivasi, Lingkungan Kerja Terhadap Kinerja Karyawan Dengan Komitmen Organisasional Sebagai Variabel Intervening. Jurnal Informasi, Perpajakan, Akuntansi, Dan Keuangan Publik, 12(2), 103-120.

Subakti, Agung Gita. (2013). Pengaruh Motivasi, Kepuasan Kerja, dan Sikap Kerja terhadap Kinerja Karyawan Di Cafe Bogor

Sugiyono. 2017. Metodelogi Penelitian.Bandung:Alfabeta

Syardiansah, S., \& Utami, M. P. (2019). Pengaruh Lingkungan, Disiplin dan Motivasi Kerja Terhadap Kinerja Karyawan PT. Pati Sari Di Aceh Tamiang. Jkbm (Jurnal Konsep Bisnis Dan Manajemen), 5(2), 197-206.

Wateknya, Y. (2016). Pengaruh Komitmen Organisasi dan Kepuasan Kerja Terhadap Turnover Intention. Jurnal Manajemen Bisnis Indonesia (JMBI), 5(5), 468-480.

Widiastuti, T., \& Suaris, S. (2017). Pengaruh Komitmen Organisasi Dan Kepuasan Kerja Terhadap Organizational Citizenship Behaviour (Ocb)(Studi pada 
Karyawan Kantor Konsultan Manajemen Rizqi). Fokus Ekonomi: Jurnal Ilmiah Ekonomi, 12(1), 81-98.

Yuliana, M., Hasiholan, L. B., \& Gagah, E. (2017). Pengaruh Lingkungan Kerja,
Disiplin Kerja, Dan Kepuasan Kerja Terhadap Kinerja Karyawan Bmt Taruna Sejahtera Ungaran. Journal of Management, 3(3). 